\title{
FEM Simulation of a FML Full Scale Aeronautic Panel Undergoing Static Load
}

\section{R. Citarella ${ }^{1}$, E Armentani $^{2}$, R Sepe ${ }^{2}$ and F Caputo ${ }^{3}$}

${ }^{1}$ Department of Industrial Engineering, University of Salerno, Fisciano (SA), Italy

${ }^{2}$ Department of Materials Engineering and Production, University of Naples, P.le V. Tecchio, 80-80125 Naples, Italy

${ }^{3}$ Dept. of Industrial and Information Engineering, Second University of Naples, via Roma $29-81031$ Aversa (CE) Italy

\begin{abstract}
This paper concerns the numerical characterization of the static strength of a flat stiffened panel, designed as a fiber metal laminates (FML) and made of Aluminium alloy and Fiber Glass FRP. The panel is full scale and was tested under static loads, applied by means of an in house designed and built multi-axial fatigue machine. The static test is simulated by the Finite Element Method (FEM) in a three-dimensional approach. The strain gauge outcomes are compared with corresponding numerical results, getting a satisfactory correlation.
\end{abstract}

Keywords: Multiaxial fatigue; FEM simulation; FML; Full scale panel

\section{Introduction}

To achieve high-performance aircraft structures new tailored and cost-effective materials are continuosly designed and tested. Nowadays the Fibres Metal Laminate (FML) technology is optimised for fatigue and damage tolerance properties, that is one of the reasons for its application in the upper shells of the A380 fusolage, but a balanced performance in terms of static properties is also obtainable, leading to a significant reduction in terms of weight and operating cost. This paper concerns an investigation on the application of innovative materials
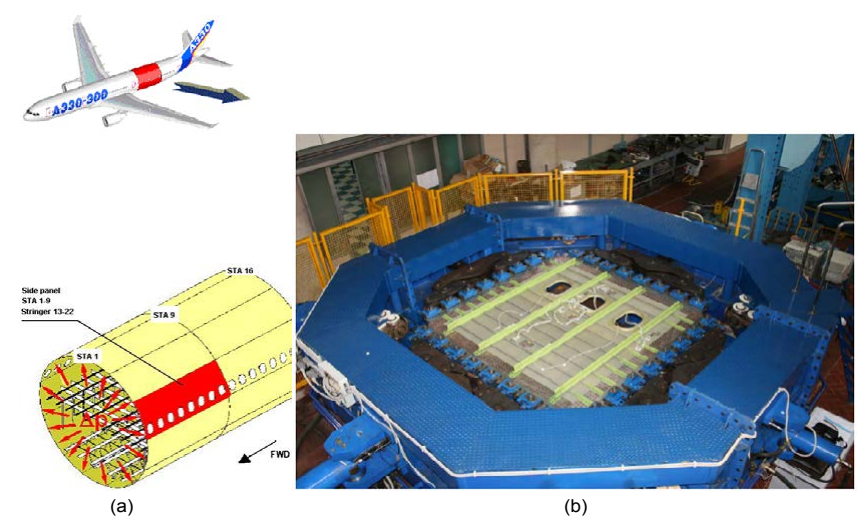

Figure 1: a-b DIALFAST barrel and tested panel loaded by the Multi-axial fatigue machine.

\begin{tabular}{|c|c|c|c|c|c|c|}
\hline PLY & MATL & $\begin{array}{c}\text { SKIN } \\
\text { ORIENT. }\end{array}$ & $\begin{array}{c}\text { STRINGER } \\
\text { ORIE. }\end{array}$ & $\begin{array}{c}\text { THK } \\
\text { [mm }\end{array}$ & Component & Material \\
\hline P1 & LAMINA & N/A & N/A & 0.3 & Lamina Skin & Alloy 7475- T761 \\
\hline P2 & F/G & $0^{\circ}$ & $0^{\circ}$ & 0.125 & FG Prepreg & FG FM 94-22\%- \\
S2 GLASS $-187-460$
\end{tabular}

Table 1: a-b Skin and stringer lay-up and adopted material. obtained by the use of improved lamina and fibre reinforcements (FML) to panels of a typical wide body fuselage section. The requirements for a numerical model, based on the Finite Element Method (FEM), capable of assessing the static behaviour of selected details made of FML (Glare is an example of such hybrid material with considerably good damage tolerance properties), are provided. The forward side panel of the DIALFAST fuselage has been considered (DIALFAST is acronym of Development of Innovative and Advanced Laminates for Future Aircraft Structures, an European project in which such panel was developed and analysed).

\section{Panel description and experimental test}

A Metal Barrel, which is representative of Airbus A330/340 fuselage section 16 (Figure 1a), has been considered as a reference structure in order to define the design solution for a stiffened panel made of innovative FML. The panel, whose dimensions are 2181 x 2181 $\mathrm{mm}$ (excluding the aluminium gripping plates), consists of three bays joined together by butt-straps and $\mathrm{z}$-shape stringer coupling; windows cut-outs are included in the structure (Figure $1 \mathrm{~b}$ ). The stringer pitch and the frame pitch are equal to, respectively, $172.3 \mathrm{~mm}$ and $533 \mathrm{~mm}$. The panel is made of two parts: an upper and a lower panel, joined by a lap joint at the stringer N.4 (Figure 2). The frames are applied on both panel sides to minimize the secondary bending effects. In detail the panel consists of the following parts: FML skin, FML stringers bonded to the skin, metallic frames and cleats ( $\mathrm{Al} 2024-\mathrm{T} 3$ clad sheet) riveted to the skin, metallic window frames (7075 - T651 Hand forming) bonded to the skin. (Tables $1 \mathrm{a}$ and $1 \mathrm{~b})$ show the FML skin $\left(3 / 2-0.3 \mathrm{~mm}-0^{\circ} / 90^{\circ}\right)$ and stringer $\left(3 / 2-0.3 \mathrm{~mm}-0^{\circ} / 0^{\circ}\right)$ layups and the used materials. The tested panel has been instrumented with strain gages that are located on both sides in order to provide information about the secondary bending relevance. Specifically ten strain rosettes with three legs disposed at $0^{\circ}$ -

${ }^{*}$ Corresponding author: $\mathrm{R}$ Citarella, Department of Industrial Engineering, University of Salerno, Fisciano (SA), Italy, E-mail: rcitarella@unisa.it

Received December 10, 2013; Accepted January 22, 2014; Published January 29, 2014

Citation: Citarella R, Armentani E, Sepe R, Caputo F (2014 FEM Simulation of a FML Full Scale Aeronautic Panel Undergoing Static Load. Ind Eng Manage 3: 122. doi: 10.4172/2169-0316.1000122

Copyright: ( $) 2014$ Citarella R, et al. This is an open-access article distributed under the terms of the Creative Commons Attribution License, which permits unrestricted use, distribution, and reproduction in any medium, provided the original author and source are credited. 


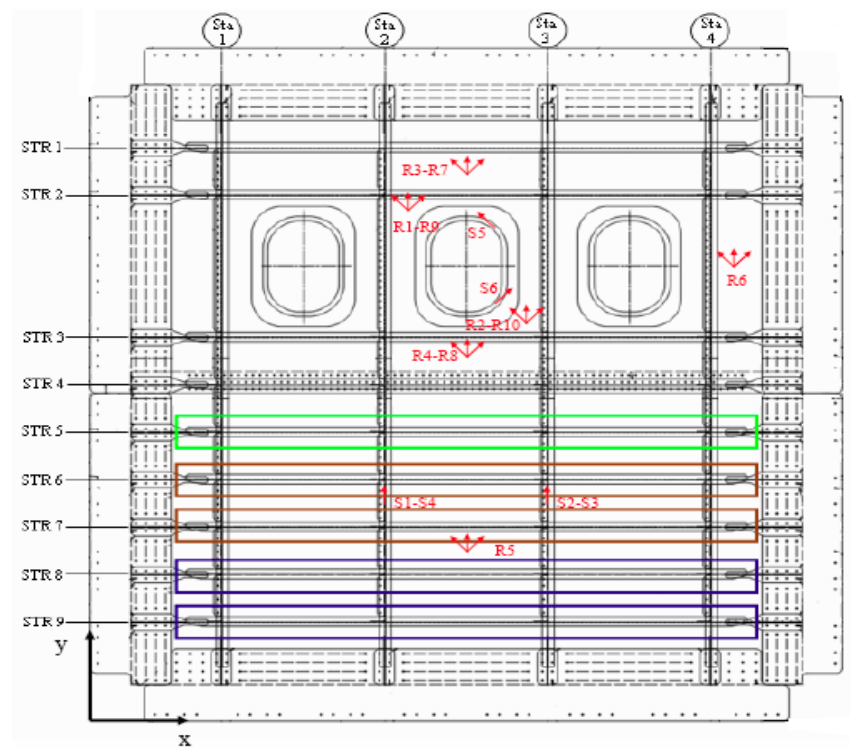

Figure 2: Strain gage and rosette configuration on side $\mathrm{A}$.

\begin{tabular}{|c|c|c|c|c|c|c|c|c|}
\hline Side A & R1 & R2 & R3 & R4 & R5 & R6 & S1 & S2 \\
\hline $\mathrm{x}[\mathrm{mm}]$ & 1017 & 1430 & 1220 & 1220 & 1220 & 2104 & 970 & 1500 \\
\hline $\mathrm{y}[\mathrm{mm}]$ & 1835 & 1475 & 2010 & 1320 & 631 & 1655 & 787 & 787 \\
\hline Side B & R7 & R8 & R9 & R10 & S3 & S4 & S5 & S6 \\
\hline $\mathrm{x}[\mathrm{mm}]$ & 1220 & 1220 & 1017 & 1430 & 1500 & 970 & 1332 & 1332 \\
\hline $\mathrm{y}[\mathrm{mm}]$ & 2010 & 1320 & 1835 & 1475 & 787 & 787 & 1767 & 1543 \\
\hline
\end{tabular}

Table 2: Strain gages and rosette positions on sides $A$ and $B$ of the panel.

$45^{\circ}-90^{\circ}$ (type CEA-13-250UR-350) and 8 strain gages (type CEA-13250UW-350) were installed on the specimen. The strain gages were bonded on both sides of the panel (side A and B) by a two-component epoxy adhesive in order to assure good performance also with large strains. The layout of strain rosettes and strain gages on the side $\mathrm{A}$ is shown in (Figure 2); whereas the positioning coordinates $(x, y)$ of strain gages and rosettes are reported in (Table 2). The tested specimen has been subjected to a load test (load values are taken from previous studies developed within DIALFAST project) by the Multiaxial test machine shown in (Figure 1b) [1]. Eight clamps on each side of the panel transfer the load by 4 properly shaped pins, either by shear or by pin clamping friction. The 8 clamps are linked by a lever system to their respective traction load-applying cylinders. To apply the external loads without causing damages on the panel borders, six aluminium plates are joined to the panel. This loading system allows independent deformations along different directions on the skin plane. The same set of grips applies both normal and shear loads; a balancing system assures that the normal load is uniformly distributed on the edge. The boundary conditions are "simply supported edges" constraints, i.e. the in-plane displacements are allowed, whereas the out-of-plane displacements at the panel edges are constrained by means of a rolling bearing system. Loads are applied along one direction by two hydraulic cylinders and the maximum value is equal to $\mathrm{P}_{\mathrm{y}}=250 \mathrm{kN}$, with loads applied in load control with a ramp of $1 \mathrm{kN} / \mathrm{sec}^{\mathrm{y}}$.

\section{FEM model}

The FEM model (Figure 3) is based on 194983 nodes belonging to 227451 elements. More in details: 199862 shell elements (Shell 181 from the ANSYS element library) with 4 nodes to model skin and stiffeners, 2377 beam elements (Beam4) to simulate the rivets whereas the remaining 25212 are spring elements (Combin14) to simulate the bonding between the two joined skins (Figure 4).

The shell elements adopted for the skin modelling incorporates the properties of each single FML layer (Figure 3): in particular the composite layer has the mechanical properties listed in (Table 3). A geometric non linear static analysis was developed [2-3].

\section{Results}

The FEM contour plots of strains in the directions provided by the strain gauges are shown in (Figure 5) and can be compared with the corresponding Boundary Element Method (BEM) [4-7] results presented in [8]. In (Table 4) the strains calculated by the FEM analysis are compared with the corresponding values coming from measurements on the test article.

The correlation between numerical (FEM) and experimental results is judged satisfactory but some margins of improvements are still
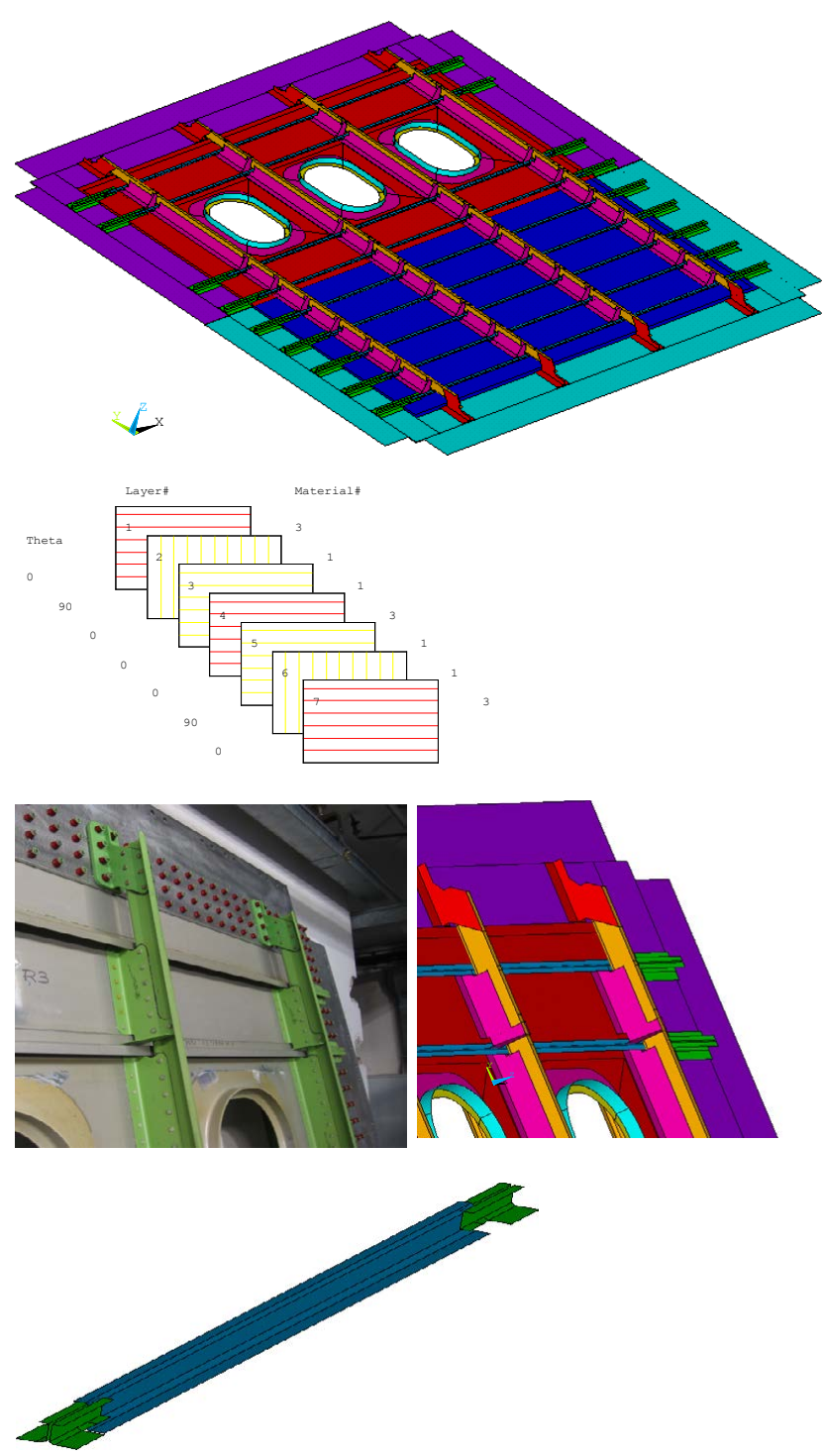

Figure 3: FE geometric model: global view with highlight of skin layers (up) and details of stringer and frame connection to the underlying skin (down). 

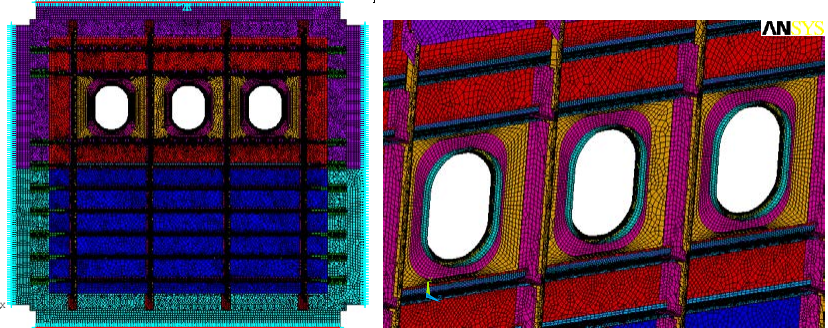

Figure 4: Overall FEM model with mesh close-up around the windows.

\begin{tabular}{|c|c|c|c|c|c|c|c|c|c|}
\hline $\mathrm{E}_{1}$ & $\mathrm{E}_{2}$ & $\mathrm{E}_{3}$ & $\mathrm{~V}_{12}$ & $\mathrm{~V}_{13}$ & $\mathrm{~V}_{23}$ & $\mathrm{G}_{12}$ & $\mathrm{G}_{13}$ & $\mathrm{G}_{23}$ & $\rho$ \\
\hline $\mathrm{GPa}$ & $\mathrm{GPa}$ & $\mathrm{GPa}$ & {$[-]$} & {$[-]$} & {$[-]$} & $\mathrm{GPa}$ & $\mathrm{GPa}$ & $\mathrm{GPa}$ & $\mathrm{kg} / \mathrm{mm}^{3}$ \\
\hline 53.2 & 9.3 & 9.3 & 0.279 & 0.279 & 0.49 & 5.495 & 5.495 & 3.121 & $1.974 .10^{-6}$ \\
\hline
\end{tabular}

Table 3: Mechanical properties of FG FM 94-27\%-S2-Glass-187-460.
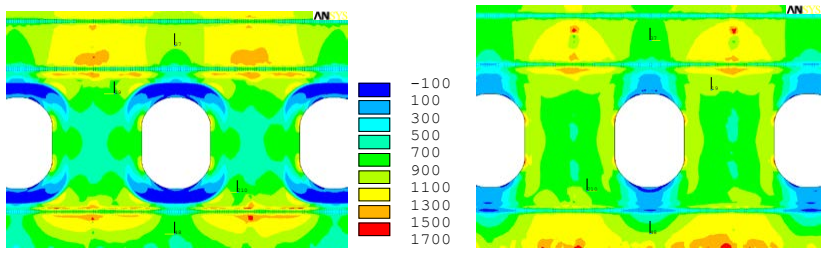

R1-2, R2-2, R3-2, R4-2 (side A)

R1-2, R2-2, R3-2, R4-2 (side A)
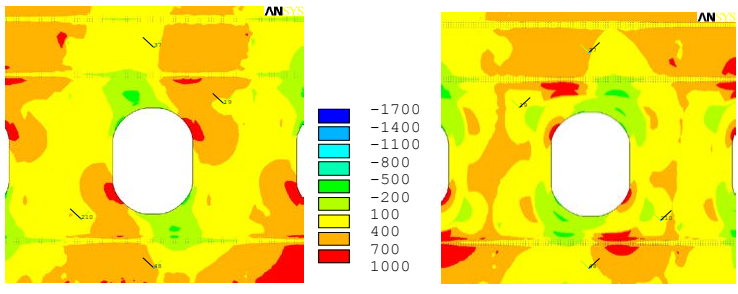

R7-1, R8-1, R9-1, R10-1 (side B)
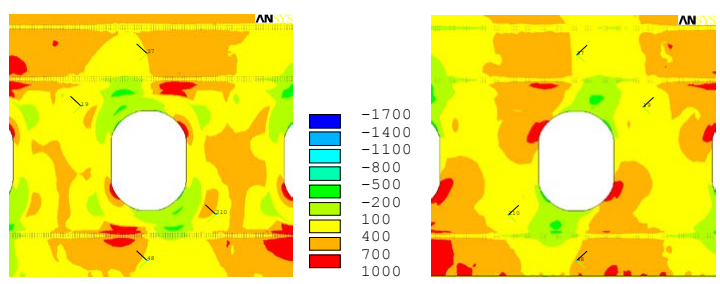

R1-1, R2-1, R3-1, R4-1 (side A)

R7-3, R8-3, R9-3, R10-3 (side B)
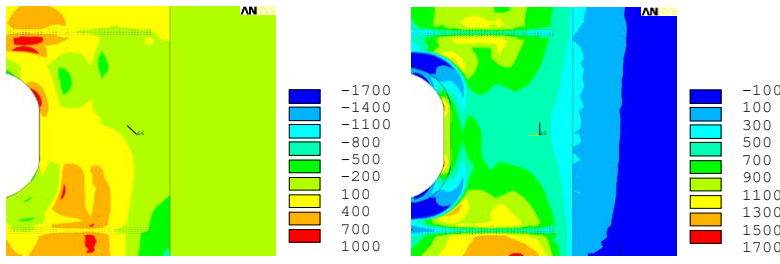

R6-1 (side A)

R6-2 (side A)

Figure 5: Contour plot of strains [ ] in the direction defined by the corresponding strain gauges (listed in the captions of each image).

available, considering that a simplified two dimensional BEM approach (characterized by a straightforward modeling and meshing process) allowed analogous accuracy [8]. The next step will be the introduction of a crack in the model and the simulation of its propagation with the approach used in [9-10].

\section{Conclusions}

Even if in most of the strain gauge positions the correlation between numerical and experimental deformations is satisfactory, there is still some needed work to improve the FEM model as pointed out by the mismatch between the strains calculated and measured on positions R1-1, R1-3, R2-1, R10-1, R4-1, and R6-3. Sometimes the reason of the aforementioned mismatch can be found in a failure or malfunctioning of the involved strain gauge whereas in other cases it depends on the numerical model accuracy: the precise assessment of the two cases is currently under investigation.

Some margins of simplification of the FEM model have been already devised and could consist in the replacement of the detailed rivet connection (hundreds of rivets have been explicitly modelled) with continuous bonding between the layers in which the "density" of such rivets is sufficiently high.

\begin{tabular}{|c|c|c|c|}
\hline Strain gauge & $\begin{array}{c}\text { Experimental strain } \\
{[\mu \mathrm{m}]}\end{array}$ & Numerical strain $[\mu \mathrm{m}]$ & Error (\%) \\
\hline R1-1 & 156 & 287 & $84 \%$ \\
\hline $\mathrm{R} 1-2$ & 806 & 881 & $9 \%$ \\
\hline R1-3 & 285 & 213 & $-25 \%$ \\
\hline R9-1 & 307 & 267 & $-13 \%$ \\
\hline R9-2 & 883 & 945 & $7 \%$ \\
\hline R9-3 & 335 & 393 & $17 \%$ \\
\hline $\mathrm{R} 2-1$ & 82 & 377 & $360 \%$ \\
\hline $\mathrm{R} 2-2$ & 839 & 854 & $2 \%$ \\
\hline R2-3 & 316 & 275 & $-13 \%$ \\
\hline R10-1 & 253 & 380 & $50 \%$ \\
\hline R10-2 & 809 & 883 & $9 \%$ \\
\hline R10-3 & 243 & 227 & $-7 \%$ \\
\hline R3-1 & 408 & 361 & $-12 \%$ \\
\hline R3-2 & 892 & 823 & $-8 \%$ \\
\hline R3-3 & 369 & 358 & $-3 \%$ \\
\hline $\mathrm{R} 7-1$ & 387 & 415 & $7 \%$ \\
\hline R7-2 & 902 & 925 & $3 \%$ \\
\hline R7-3 & 414 & 411 & $-1 \%$ \\
\hline $\mathrm{R} 4-1$ & 343 & 450 & $31 \%$ \\
\hline $\mathrm{R} 4-2$ & 927 & 925 & $0 \%$ \\
\hline R4-3 & 368 & 420 & $14 \%$ \\
\hline R8-1 & 340 & 337 & $-1 \%$ \\
\hline R8-2 & 788 & 723 & $-8 \%$ \\
\hline R8-3 & 285 & 340 & $19 \%$ \\
\hline R5-1 & 357 & 405 & $13 \%$ \\
\hline R5-2 & 986 & 1079 & $9 \%$ \\
\hline R5-3 & 355 & 420 & $18 \%$ \\
\hline R6-1 & 43 & 43 & $0 \%$ \\
\hline R6-2 & 498 & 554 & $11 \%$ \\
\hline R6-3 & 270 & 392 & $45 \%$ \\
\hline S1 & 915 & 1004 & $10 \%$ \\
\hline S4 & 787 & 740 & $-6 \%$ \\
\hline S2 & 1000 & 1069 & $7 \%$ \\
\hline S3 & 849 & 752 & $-11 \%$ \\
\hline S5 & 612 & 698 & $14 \%$ \\
\hline S6 & 639 & 761 & $19 \%$ \\
\hline S7 & -141 & -136 & $-4 \%$ \\
\hline S8 & -133 & -147 & $11 \%$ \\
\hline
\end{tabular}

Table 4: Numerical (FEM) and experimental correlation. 
Citation: Citarella R, Armentani E, Sepe R, Caputo F (2014 FEM Simulation of a FML Full Scale Aeronautic Panel Undergoing Static Load. Ind Eng Manage 3: 122. doi: 10.4172/2169-0316.1000122

\section{References}

1. Armentani E, Caputo F, Esposito R., Godono G (2001) A new three loading axes machine for static and fatigue tests. Proceedings of the Sixth International Conference on Biaxial/Multiaxial Fatigue \& Fracture (6th ICBMFF), 1: 323-330, Lisboa, Portugal.

2. Caputo F, Esposito R, Perugini P, Santoro D (2002) Numerical-Experimental Investigation On Post-Buckled Stiffened Composite Panels. Composite Structures 55: 347-357.

3. Calì C, Cricrì C, Perrella M (2010) Post-Buckling Behaviour of Thin Aluminium Panels undergoing Shear Load: Experimental and Numerical Investigation. Civil-Comp Press, Stirlingshire, UK.

4. Citarella R, Cricrì G, Armentani E (2013) Multiple Crack Propagation With Dual Boundary Element Method In Stiffened And Reinforced Full Scale Aeronautic Panels. Key Engineering Materials 560: 129-155.

5. Citarella R (2009) Non Linear MSD Crack Growth by DBEM for A Riveted Aeronautic Reinforcement. Advances in Engineering Software 40: 253-259.
6. Armentani E, Citarella R (2006) DBEM And FEM Analysis On Non-Linear Multiple Crack Propagation In An Aeronautic Doubler-Skin Assembly. Int $J$ Fatigue 28: 598-608.

7. Citarella $R$ (2011) MSD Crack propagation on a repaired aeronautic panel by DBEM. Adv Eng Softw 42: 887-901.

8. Armentani E, Citarella R, Sepe R (2011) FML Full Scale Aeronautic Pane Under Multiaxial Fatigue: Experimental Test And DBEM Simulation. Eng Fract Mech 78: 1717-1728.

9. Armentani E, Caputo F, Esposito R, Godono G (2004) Evaluation Of Energy Release Rate For Delamination Defects At The Skin/Stringer Interface Of A Stiffened Composite Panel. Eng Fract Mech 71: 885-895.

10. Riccio A, Caputo F, Tessitore N (2013) Intra-laminar Damage Evolution in a Composite Grid Structure Representative Volume Element under Compression Load. Structural Durability \& Health Monitoring 9: 43-66. 